\title{
Body image and healthy lifestyle behaviors of university students
}

\author{
Michele S. Bednarzyk, Tracy L. Wright, Kathaleen C. Bloom* \\ $D N P F N P-B C$ \\ $M S N F N P-B C$ \\ PHD CNM \\ *Corresponding author E-mail: kbloom@unf.edu
}

\begin{abstract}
Background: Body image, one's perception of personal physical appearance, can be positive or negative, leading to body satisfaction or body dissatisfaction. Body satisfaction and dissatisfaction affect individuals of all ages and have the potential to impact lifestyle choices.

Objectives: The purpose of this study was to identify the relationship between body image and healthy lifestyle behaviors.

Participants: Undergraduate students at a state university in the southeastern United States.

Methods: An email was sent, providing a link to an online survey that included: demographic, body image, and screen time questions; the Moderate to Vigorous Physical Activity tool; and the Health Promoting Lifestyle Profile II.

Results: 1,056 usable surveys were returned. The participants were primarily Caucasian females $(75 \%)$ who were college juniors or seniors $(65.5 \%)$. The majority $(71 \%)$ indicated they were satisfied with their body, although many $(60.3 \%)$ wanted to alter it. Most $(65.1 \%)$ had a normal BMI. Only $23.3 \%$ meet physical activity guidelines. Healthy lifestyle behaviors were engaged in "sometimes" and "often, but not routinely." Body image was correlated with healthy lifestyle behaviors.

Conclusions: Programs and resources focusing on promotion of positive body image, appropriate physical activity, and healthy eating behaviors should be the norm on college campuses.
\end{abstract}

Keywords: Body image, health education, health promotion, lifestyle behaviors, weight perception.

\section{Introduction}

Young people often feel a tremendous amount of pressure to have a body that meets the expectations of their parents, their peers, and society. When their body does not conform to these expectations, either in reality or in self-perception, their satisfaction with their body [1] and their self-esteem [2], [3] are affected. Those who have been teased about their weight [2], [4] and those who are overweight or perceive themselves to be overweight also tend to have poorer body image and greater dissatisfaction with their bodies [2], [5].

Body image and satisfaction may vary based on socioeconomic status, age, and gender. Young people with higher SES tend to have a smaller ideal body size, although SES may or may not influence perception of personal body size [6]. [7]. In general, Asian, Caucasian, and Hispanic females are more likely to feel dissatisfied with their bodies than blacks [811]. Caucasian males report a higher level of body satisfaction than all other ethnicities [10]. Repeated exposure to persons who are overweight or obese can influence an individual's own perceptions related to weight. Underestimation of personal weight status is higher in young people whose parents and/or classmates have higher BMIs [12]. Some actually report they become so used to seeing overweight individuals they are no longer aware of weight [13].

Body dissatisfaction has been linked to low self-esteem [1] and a higher BMI [2], and depressive symptoms have been associated with a perception of not being the appropriate weight [14] with females reporting more depressive symptoms than males [15]. Body dissatisfaction is also a risk factor for development and maintenance of eating disorders [16], [17] and for worsening of disordered eating among college students [18].

Healthy lifestyle behaviors are those behaviors that demonstrate responsibility for one's own health, taking part in physical activity, having adequate nutritional intake, realizing self-actualization, establishing interpersonal relations, and learning how to manage stress [19]. Diet, exercise, and stress management have been recognized as some of the major behaviors to target for analysis in the young adult age group, since prevention at an early stage in life is paramount to remaining healthy in later years when the risks for disease are so much higher [20], [23]. 
Young people who are attending a university are dealing with many pressures, including being away from home for the first time. They are required to make more independent decisions, which can be stressful. Among the decisions these students must make are those related to healthy lifestyles, including nutrition and physical activity. There may or may not be a relationship between gender and nutritional knowledge among university students [24], [25]. It is clear, however, that there no relationship between university students' knowledge of healthy food and their nutritional habits [25]. Living situations can affect the eating habits of these students, with those living off campus having lower fruit and vegetable consumption than those living on campus [26].

Physical activity is also affected as students transition from high school to university, decreasing by as much as $20 \%$ [27], with further decreases across the four years at university [26]. In a meta-analysis of the physical activity behaviors of college students, 30-50\% did not engage in enough physical activity to reap the health benefits [28]. In general, male students report engaging in physical exercises more often than females [11], [23], and [24]. As with eating habits, living situations can affect the physical activity, with those living off campus having lower levels of physical activity than those living on campus [26].

According to the American College Health Association, 32.5\% of college students are either overweight or obese [29]. The transition from high school to college is often accompanied by a significant weight gain [30], [31] with cited reasons including easy access to and large portion sizes of unhealthy food, lack of time for exercise, and eating in response to stress and/or boredom [32], [33]. Overweight and obesity negatively impact body image [24] and weight is inversely related to healthy lifestyle behaviors [35], [36]. It is, therefore, important to understand both body satisfaction and lifestyle habits with respect to eating and exercise [37]. The purpose of this study was to determine the relationship between body image and healthy lifestyle behaviors among undergraduate university students.

\section{Methods}

This was a cross-sectional study employing an online survey technique to explore the relationships between body image and healthy lifestyle behaviors in university students. The setting was a university campus in the southeastern United States with a student body of 16,600 students. The majority of the students at this university are Caucasian (74\%), with $10 \%$ black, $7 \%$ Asian, and 6\% Hispanic. The school admits approximately 1,100 freshmen each fall, 57\% of whom are female. For inclusion in this study, participants were required to be: (a) enrolled as an undergraduate student; (b) $>17$ and <25 years-of-age; and (c) able to read and understand English.

\subsection{Data collection}

An email was sent out to all enrolled undergraduate students during the sixth week of the fall semester. The email included an invitation to participate and a link to an online survey created with Vovici. A reminder email was sent two weeks later to provide for increased participation of students. Electing to complete and submit the survey constituted consent to participate. The survey used a HTML form to collect responses in a secure database and responses were totally anonymous. The survey remained open for one month after the initial e-mail invitation was deployed. Institutional review board approval under expedited status was obtained prior to deployment of the survey.

\subsection{Instruments}

An online survey was used to collect demographic data as well as measures of body image and healthy lifestyle behaviors. The survey contained a total of 74 questions and took approximately 20 minutes to complete. Demographic data included the students' age, gender, ethnicity, place of abode, grade level, part-time or full-time designation, college major, work status, self-reported height and weight, and self-reported health status.

Body image was measured as a function of body dissatisfaction, using the body dissatisfaction questions developed by Wilkosz et al. [37]. There are five "Yes" "No" questions related to behaviors with respect to gaining or losing weight in the previous 7 days. Each answer is given a point value of 1 for "Yes" or 0 for "No. The points are totaled to provide the measure of body dissatisfaction. The range of possible scores is 0-35, with lower scores indicative of satisfaction with body image.

The lifestyle behaviors assessed were (1) sedentary activity, (2) physical activity, and (3) healthy lifestyle behavior. Sedentary activity was measured using screen time questions developed by Wilkosz et al. [37] eliciting self- reported time spent watching television, playing video games, and/or using the computer for leisure (not for schoolwork). These were scored based on less than or greater than two hours per day.

The 2008 Physical Activity Guidelines for Americans indicate physical activity for adolescents should be at least 60 minutes daily and that adults should engage in at least 150 minutes of moderate to vigorous physical activity (MPVA) per week [38]. For the purposes of this study, physical activity was measured using the 60-minute MVPA screening tool 
consisting of two questions querying the individual's number of days of moderate to vigorous exercise in the past week and in a typical week. The MVPA score is the average of the two questions. The tool is reliable (interclass correlation= $0.77)$ and valid ( $\mathrm{r}=0.40$ in a test against the computer science and applications accelerometer) [39].

Healthy lifestyle behavior was measured using the Health Promoting Lifestyle Profile (HPLP) II [40], [41]. There are 52 items on the HPLP II, divided into six subscales: spiritual growth, interpersonal relations, nutrition, physical activity, health responsibility, and stress management. The internal consistency of the instrument as a whole is high, with an alpha coefficient of .943. Individual subscale alpha coefficients range from .793 to .872. The stability of the instrument was found to be .892 for the total scale [41]. The scale has been widely used in studies of university students across the world [42-44]. For the purposes of this study, the scores for the total scale and the nutrition, physical activity, and health responsibility subscales were used.

\section{Results}

\subsection{Sample}

Invitations to participate in the online survey were e-mailed to 11,909 undergraduate university students. A total of 1,813 individuals logged on to the survey. Of those, $560(30.89 \%)$ only partially completed the survey. There were 148 individuals who logged on to the survey and did not complete any survey items. Out of the 1,105 individuals who completed the survey, there were 49 people who were over the age of 24 . Therefore, the final sample size was 1,056 .

The mean age of the sample was $20.47(\mathrm{SD}=1.73)$. The majority were Caucasian $(75.3 \%)$ and female $(75 \%)$. Most of the participants were upperclassmen $(65.5 \%)$, in a non-health-related major $(69.8 \%)$ and enrolled full-time $(92.5 \%)$. The majority of the participants were living on their own either on or off-campus $(64.8 \%)$ and were employed $(61.8 \%)($ See Table 1).

\begin{tabular}{|c|c|c|}
\hline Characteristic & $\mathrm{N}$ & $\%$ \\
\hline \multicolumn{3}{|l|}{ Ethnicity } \\
\hline Asian & 63 & 5.9 \\
\hline Biracial & 31 & 2.9 \\
\hline Black & 60 & 5.7 \\
\hline Caucasian & 795 & 75.3 \\
\hline Hispanic & 95 & 9.0 \\
\hline Middle Eastern & 6 & 0.6 \\
\hline Other & 6 & 0.6 \\
\hline \multicolumn{3}{|l|}{ Gender } \\
\hline Female & 792 & 75.0 \\
\hline Male & 264 & 25.0 \\
\hline \multicolumn{3}{|l|}{ College Level } \\
\hline Freshman & 174 & 16.5 \\
\hline Sophomore & 190 & 18.0 \\
\hline Junior & 388 & 36.7 \\
\hline Senior & 304 & 28.8 \\
\hline \multicolumn{3}{|l|}{ Major } \\
\hline Health-related & 319 & 30.2 \\
\hline Non health-related & 737 & 69.8 \\
\hline \multicolumn{3}{|l|}{ Enrollment Status } \\
\hline Full-time & 977 & 92.5 \\
\hline Part-time & 79 & 7.5 \\
\hline \multicolumn{3}{|l|}{ Living Situation } \\
\hline On campus & 293 & 27.7 \\
\hline Own home/apartment & 392 & 37.1 \\
\hline With parent/guardian & 371 & 35.1 \\
\hline \multicolumn{3}{|l|}{ Work Status } \\
\hline Full-time & 115 & 10.9 \\
\hline Part-time & 538 & 50.9 \\
\hline Not working & 403 & 38.2 \\
\hline
\end{tabular}


The average self-reported height was 66.18 inches (range $=57-77, \mathrm{SD}=3.77$ ), the average self-reported weight was 147.58 pounds (range $=85-345, \mathrm{SD}=34.83$ ), giving an average $\mathrm{BMI}$ of 23.58 (range $=14.56-50.48, \mathrm{SD}=4.63$ ). Of the 1,056 participants, $19.7 \%$ were overweight and $9 \%$ were obese (see Table 2 ).

Table 2: BMI distributions for the sample

\begin{tabular}{ccc}
\hline Classification & $\mathrm{N}$ & $\%$ \\
\hline Severely underweight $(<16.0)$ & 3 & 0.3 \\
Underweight (16.0-18.5) & 62 & 5.9 \\
Normal weight (18.5-25.0) & 687 & 65.1 \\
Overweight (25.0-30.0) & 208 & 19.7 \\
Obese class I (30.0-35.0) & 70 & 6.6 \\
Obese class II (35.0-40.0) & 15 & 1.4 \\
Obese class III $(>40.0)$ & 11 & 1.0 \\
\hline
\end{tabular}

\subsection{Body image}

In general, participants reported being satisfied with their body and with their weight, although more than half reported that they currently wanted to gain or lose weight (see Table 3 ). There was no difference in body image by age ( $\mathrm{F}=0.17$, $\mathrm{p}=.98)$, gender $(\mathrm{F}=0.05, \mathrm{p}=.82)$, or college major $(\mathrm{F}=2.97, \mathrm{p}=0.9)$.

Table 3: Body satisfaction

\begin{tabular}{|c|c|c|}
\hline & $\mathrm{N}$ & $\%$ \\
\hline \multicolumn{3}{|l|}{ Current Weight Loss Goals } \\
\hline Lose, or gain weight & 637 & 60.3 \\
\hline Stay same, not do anything & 419 & 39.7 \\
\hline \multicolumn{3}{|l|}{ In past 7 days, diet to gain/lose weight } \\
\hline Yes & 307 & 29.1 \\
\hline No & 749 & 70.9 \\
\hline \multicolumn{3}{|l|}{ In past 7 days, exercise to gain/lose weight } \\
\hline Yes & 518 & 49.1 \\
\hline No & 538 & 50.9 \\
\hline \multicolumn{3}{|l|}{ In past 7 days, do anything else to gain/lose weight } \\
\hline Yes & 37 & 3.5 \\
\hline No & 1,019 & 96.5 \\
\hline
\end{tabular}

Thirty-seven $(3.5 \%)$ of the participants listed activities for weight loss or gain other than diet and exercise. Some of these were healthy behaviors, some were not. Eighteen individuals used dietary supplements or weight loss aids, 8 admitted to purging, 4 avoided eating at all, 3 increased their water intake, 2 increased their hours of sleep, 1 had dental work which affected food intake, and 1 was breastfeeding.

\subsection{Healthy lifestyle behaviors}

Using the MVPA, only 268 (25.3\%) were meeting physical activity guidelines consistent with promotion of health (see Table 4). There was a significant difference in physical activity by gender $(\mathrm{F}=16.65, \mathrm{p}=.00)$, with males reporting more physical activity than females. There was no difference in physical activity by age $(\mathrm{F}=1.5, \mathrm{p}=.17)$ or college major $(\mathrm{F}=2.75, \mathrm{p}=0.1)$.

Table 4: MVPA scores for physical activity

\begin{tabular}{|c|c|c|c|c|c|c|}
\hline \multirow[b]{2}{*}{ Days } & \multicolumn{2}{|c|}{60 Minutes/Day Past 7 Days } & \multicolumn{2}{|c|}{60 Minutes/Day Typical Week } & \multicolumn{2}{|c|}{ Average Score* } \\
\hline & $\mathrm{N}$ & $\%$ & $\mathrm{~N}$ & $\%$ & $\mathrm{~N}$ & $\%$ \\
\hline 0 & 227 & 21.5 & 177 & 16.8 & 155 & 14.7 \\
\hline 1 & 131 & 12.4 & 113 & 10.7 & 131 & 12.4 \\
\hline 2 & 152 & 14.4 & 155 & 14.7 & 163 & 15.4 \\
\hline 3 & 184 & 17.4 & 207 & 19.6 & 196 & 18.6 \\
\hline 4 & 121 & 11.5 & 145 & 13.7 & 143 & 13.6 \\
\hline 5 & 96 & 9.1 & 107 & 10.1 & 110 & 10.4 \\
\hline 6 & 63 & 6.0 & 78 & 7.4 & 84 & 7.9 \\
\hline 7 & 82 & 7.8 & 74 & 7.0 & 74 & 7.0 \\
\hline
\end{tabular}


During a typical school week, $74.7 \%$ of participants used a computer for recreational purposes greater than the 2-hours of recommended time per day. The percentage of participants who used a computer for recreational purposes for greater than the recommended time per day was only slightly less on the weekends (68\%). Only $34.5 \%$ of the sample excessively watched television and/or played video games during the school week, but this percentage increased to $48.5 \%$ on the weekends (see Table 5).

Table 5: Screen time

\begin{tabular}{|c|c|c|c|c|}
\hline \multirow[b]{2}{*}{ Days } & \multicolumn{2}{|c|}{ TV/Video Games } & \multicolumn{2}{|c|}{ Computer } \\
\hline & $\mathrm{N}$ & $\%$ & $\mathrm{~N}$ & $\%$ \\
\hline \multicolumn{5}{|c|}{ Monday-Friday } \\
\hline$\leq 2$ hours & 692 & 65.5 & 267 & 25.3 \\
\hline$\overline{3}-5$ hours & 253 & 24.0 & 467 & 44.2 \\
\hline $6-8$ hours & 41 & 3.9 & 132 & 12.5 \\
\hline 9-10 hours & 33 & 3.1 & 59 & 5.6 \\
\hline$>10$ hours & 37 & 3.5 & 131 & 12.4 \\
\hline \multicolumn{5}{|c|}{ Saturday-Sunday } \\
\hline$\leq 2$ hours & 544 & 51.5 & 338 & 32.0 \\
\hline$\overline{3}-5$ hours & 376 & 35.6 & 445 & 42.1 \\
\hline 6-8 hours & 88 & 8.3 & 169 & 16.0 \\
\hline 9-10 hours & 26 & 2.5 & 52 & 4.9 \\
\hline$>10$ hours & 22 & 2.1 & 52 & 4.9 \\
\hline
\end{tabular}

Cronbach's alpha for the total score on the HPLP II in the current sample was .94, indicating high internal consistency. Healthy lifestyle behaviors related to health responsibility, physical activity, and nutrition, were performed more often than never, but not routinely, for this sample (see Table 6). Women had slightly higher HPLP II scores (2.69) than did men $(2.49 ; \mathrm{F}=15, \mathrm{p}=0)$ and health-related college majors had slightly higher scores (2.69) than did non-health-related majors $(2.54 ; \mathrm{F}=25.41, \mathrm{p}=0)$. There was no difference in healthy lifestyle behaviors by age $(\mathrm{F}=-1 / 19, \mathrm{p}=.31)$.

Table 6: HPLP II scores for lifestyle behaviors

\begin{tabular}{ccc}
\hline & Mean & SD \\
\hline Overall Score & 2.59 & 0.45 \\
Health responsibility & 2.09 & 0.61 \\
Physical activity & 2.40 & 0.67 \\
Nutrition & 2.53 & 0.56 \\
\hline
\end{tabular}

\subsection{Relationship between body image and healthy lifestyle behaviors}

There was a low, but significant positive correlation between body image and some of the healthy lifestyle behaviors, the highest of which was with the physical activity subscale (see Table 7). There was a moderate correlation between MVPA scores and a health promoting lifestyle (Rho $=.37 ; \mathrm{p}=0$ ) and a low but significant correlation between MVPA scores and body image $(\mathrm{Rho}=.20, \mathrm{p}=0)$. Sedentary activity was not significantly correlated with body image, but it had a low, yet significant, negative correlation to health promoting lifestyle total $(\mathrm{Rho}=.10 ; \mathrm{p}=.02)$.

Table 7: Correlations among variables

\begin{tabular}{ccc}
\hline & \multicolumn{2}{c}{ Body Satisfaction } \\
\cline { 2 - 3 } & Spearman's Rho & 0.033 \\
\hline Health promoting lifestyle & 0.066 & 0.047 \\
Health responsibility & 0.061 & 0.000 \\
Physical activity & 0.236 & 0.003 \\
Nutrition & 0.091 & 0.000 \\
MVPA & 0.203 & 0.404 \\
Sedentary activity & -0.026 & \\
\hline
\end{tabular}




\section{Discussion}

The findings of a relationship between body image and healthy lifestyle behaviors are consistent with previous studies [8], [37]. Although more than 70\% of participants in this study reported being satisfied with their body and more than $90 \%$ reported satisfaction with their weight, $60 \%$ reported wanting to do something to gain or lose weight, suggesting some level of body dissatisfaction. Perhaps after more specific questioning about wanting to gain or lose weight, participants realized that they were, in fact, not entirely satisfied with their body. The Youth Risk Behavior Surveillance studies have found similar trends [8], that is, the number of individuals wanting to do something to alter their weight is not proportional to the number reporting dissatisfaction with their bodies.

Interestingly, although the majority wanted to lose or gain weight, most participants reported not having done anything in the previous 7 days to work toward that goal. Of those who had, strategies such as purging and avoiding food altogether, although infrequently reported by this sample, are of particular concern from a health as well as an educational perspective.

One of the most bothersome findings of the study was that only one-fourth of participants met physical activity guidelines. This is consistent with findings in multiple other studies of university students [23], [27], [28], [45]. The most time-consuming sedentary activity was recreational computer use (versus television watching). The excessive time spent on the computer might be attributed to the fact that this survey was conducted with a university population that most likely depends heavily on computers for functionality in school. Although the survey question itself specified computer use not related to school-work, it might have been difficult for this population to differentiate.

\subsection{Limitations}

The survey was rather lengthy, and the response rate may have been higher if there were not as many items to be answered. Thirty-one percent of those who logged in to the site did not complete the entire survey; their data could not be considered in the final data analysis. There were several other surveys that were sent by the university to these same students during the time that this study was done. This may have also contributed to the low response rate. Although 1,056 is a good sample size, it represents only about $10 \%$ of the available university population.

The study population was limited to one university. It would be beneficial to administer this survey across various settings within the same age group to compare students at other institutions as well those who are not enrolled in a university. Their behaviors could be different, and it would be interesting to recognize and study any differences that may exist in these populations.

\subsection{Implications}

Because college is such a transitional period for young adults, it is a critical time to identify any barriers to healthy lifestyles for these individuals. The cyclical nature of poor body image and decreased engagement in healthy lifestyle behaviors must be stopped sooner in the downward progression. Healthcare providers should take the opportunity to assess lifestyle behaviors of all young people as they prepare to enter colleges and/or the work force and refer these young people to appropriate resources within the community.

Programs focusing on the promotion of a healthy body image and healthy lifestyle behaviors should be part of the normal milieu on college campuses. Such programs would appropriately include the elements of physical activity and healthy eating behaviors.

Adequate facilities for exercise and various activities that promote physical activity and social interaction, such as intermural sports. These resources should be advertised in such a way that the students are aware of the opportunities. A variety of options should be offered so that those who are less likely to exercise in front of a large group of people will have an opportunity to exercise. This could be solved by offering extended hours in the gym facilities for those who might like to exercise when the gym is less crowded. Student ambassadors could be recruited to lead activity groups in a judgment-free atmosphere.

The food choices offered on campus should be analyzed for nutritional value. Healthy choices need to be abundant and easily available with the less healthy choices more limited. Support groups for those struggling with body satisfaction, weight issues and/or unhealthy weight management habits should be available and accessible. Education should also be provided to young adults regarding the link between unhealthy lifestyle behaviors and the development of obesity and chronic disease later in life so that awareness is raised for the importance of instituting healthy behaviors in the prevention phase of disease.

On a cautionary note, using methods of motivation for behavior change that decrease individuals' comfort with their own bodies May actually lead poor body image [46]. Since body dissatisfaction may actually have a negative effect on engaging in healthy behaviors such as physical activity and eating behaviors, educational and support programs should be aimed at promoting body satisfaction as well as healthy weight and healthy behaviors. 


\section{References}

[1] K. Presnell, S.K. Bearman, E. Stice, Risk factors for body dissatisfaction in adolescent boys and girls: a prospective study, International Journal of Eating Disorders 36 (2004) 389-401. Available online: http://dx.doi.org/10.1002/eat.20045

[2] S.J. Paxton, M.E. Eisenberg, D. Neumark-Sztainer, Prospective predictors of body dissatisfaction in adolescent girls and boys: a five-year longitudinal study, Developmental Psychology 42 (2006) 888-899. http://dx.doi.org/10.1037/0012-1649.42.5.888.

[3] P. van den Berg, S.J. Paxton, H. Keery, M. Wall, J. Guo, D. Neumark-Sztainer, Body dissatisfaction and body comparison with media images in males and females, Body Image 4 (2007) 257-268. Available online: http://dx.doi.org/10.1016/j.bodyim.2007.04.003.

[4] R.H. Salk, R. Engeln-Maddox, "If you're fat then I'm humongous": frequency, content, and impact of fat talk among college women. Psychology of Women Quarterly 35 (2011) 18-25. Available online: http://dx.doi.org/10.1177/0361684310384107.

[5] D. Neumark-Sztainer, M. Story, P.J. Hannan, C.L. Perry, L.M. Irving, Weight-related concerns and behaviors among overweight and nonoverweight adolescents: implications for preventing weight-related disorders. Archives of Pediatric Adolescent Medicine 156 (2002) 171178. Available online: http://dx.doi.org/10.1001/archpedi.156.2.171.

[6] E. Lynch, K. Liu, B. Spring, A. Hankinson, G.S. Wei, P. Greenland, Association of ethnicity and socioeconomic status with judgments of body size: the Coronary Artery Risk Development in Young Adults (CARDIA) Study, American Journal of Epidemiology 165 (2007) 1055 1062. Available online: http://dx.doi.org/10.1093/aje/kwk114.

[7] E. Park, Overestimation and underestimation: adolescents' weight perception in comparison to BMI-based weight status and how it varies across socio-demographic factors, Journal of School Health 81 (2011) 57-64. Available online: http://dx.doi.org/10.1111/j.17461561.2010.00561.

[8] D.K. Eaton, L. Kann, S. Kinchen, et al., Youth risk behavior surveillance - United States, 2011, Morbidity and Mortality Weekly Report Surveillance Summary 61 (2012) 1-162. Available online: http://www.cdc.gov/mmwr/preview/mmwrhtml/ss6104a1.htm.

[9] L.R. Jones, E. Fries, S.J. Danish, Gender and ethnic differences in body image and opposite sex figure preferences of rural adolescents, Body Image 4 (2007) 103-108. doi: 10.1016/j.bodyim.2006.11.005.

[10] D. Neumark-Sztainer, J. Croll, M. Story, P.J. Hannan, S.A. French, C. Perry, Ethnic/racial differences in weight-related concerns and behaviors among adolescent girls and boys: findings from Project EAT, Journal of Psychosomatic Research 53 (2002) 963-874. Available online: http://dx.doi.org/10.1016/S0022-3999(02)00486-5

[11] A. Yates, J. Edman, M. Aruguete, Ethnic differences in BMI and body/self-dissatisfaction among Whites, Asian subgroups, Pacific Islanders, and African-Americans, Journal of Adolescent Health 34 (2004), 300-307. Available online: http://dx.doi.org/10.1016/j.jadohealth.2003.07.014.

[12] K. Maximova, J.J. McGrath, T. Barnett, J. O'Loughlin, G. Paradis, M. Lambert, Do you see what I see? Weight status misperception and exposure to obesity among children and adolescents, International Journal of Obesity (London) 32 (2008) 1008-1015. Available online: http://dx.doi.org/10.1038/ijo.2008.15.

[13] K.J. Williams, C.A. Taylor, K.N. Wolf, R.F. Lawson, R. Crespo, Cultural perceptions of healthy weight in rural Appalachian youth, Rural Remote Health 8 (2008):932. Available online: http://www.rrh.org.au/articles/subviewnew.asp?ArticleID=932.

[14] J. Daniels, Weight and weight concerns: are they associated with reported depressive symptoms in adolescents? Journal of Pediatric Health Care 19 (2005) 33-41. Available online: http://dx.doi.org/ 10.1016/j.pedhc.2004.07.007.

[15] P. Martyn-Nemeth, S. Penckofer, M. Gulanick, B. Velsor-Friedrich, F.B. Bryant, The relationships among self-esteem, stress, coping, eating behavior, and depressive mood in adolescents, Research in Nursing and Health 32 (2009) 96-109. DOI: 10.1002/nur.20304.

[16] E. Stice, H.E. Shaw, Role of body dissatisfaction in the onset and maintenance of eating pathology: a synthesis of research findings, Journal of Psychosomatic Research 53 (2002) 985-993. Available online: http://dx.doi.org/10.1016/S0022-3999 (02)00488-9.

[17] R.H. Striegel-Moore, C.M. Bulik, Risk factors for eating disorders, The American Psychologist 62 (2007) 181-198. Available online: http://dx.doi.org/10.1037/0003-066X.62.3.181.

[18] E. Cooley, T. Toray, Body image and personality predictors of eating disorder symptoms during the college years, International Journal of Eating Disorders 30 (2001) 28-36. Available online: http://dx.doi.org/10.1002/eat.1051.

[19] R. Hacıhasanoğlu, A. Yıldırım, P. Karakurt, R. Sağlam, Healthy lifestyle behaviour in university students and influential factors in eastern Turkey, International Journal of Nursing Practice 17 (2011) 43-51. Available online: http://dx.doi.org/10.1111/j.1440-172X.2010.01905.x.

[20] P. Deshmukh-Taskar, T.A. Nicklas, M. Morales, S.J. Yang, I. Zakeri, G.S. Berenson, Tracking of overweight status from childhood to young adulthood: The Bogalusa Heart Study, European Journal of Clinical Nutrition 60 (2006) 48-57. Available online: http://dx.doi.org/10.1038/sj.ejcn.1602266.

[21] K.F. Ferraro, R.J. Thorpe Jr., and J.A. Wilkinson, The life course of severe obesity: does childhood overweight matter? The Journals of Gerontolology. Series B, Psychological Sciences and Social Sciences 58 (2003) S110-S119. Avaialble online: http://www.ncbi.nlm.nih.gov/pmc/articles/PMC3358723/.

[22] A.T. Kozak, M.L. Daviglus, C. Chan, C.I. Kiefe, D.R. Jacobs, K. Liu, Relationship of body mass index in young adulthood and health-related quality of life two decades later: the Coronary Artery Risk Development in Young Adults study, International Journal of Obesity 35 (2011) 134-141. Available online: http://dx.doi.org/10.1038/ijo.2010.120.

[23] R.L. Lee, A.J. Loke, Health-promoting behaviors and psychosocial well-being of university students in Hong Kong, Public Health Nursing 22 (2005) 209-220. Available online: http://dx.doi.org/10.1111/j.0737-1209.2005.220304.x.

[24] I. Tirodimos, I. Georgouvia, T.N. Savvala, E. Karanika, D. Noukari, Healthy lifestyle habits among Greek university students: differences by sex and faculty of study, Eastern Mediterranean Health Journal 15 (2009) 722-728. Available online: http://www.emro.who.int/emhjlist/emhj-volume-15-2009/vol15-issue3.html.

[25] M.I. von Bothmer, B. Fridlund, Gender differences in health habits and in motivation for a healthy lifestyle among Swedish university students, Nursing \& Health Sciences 7 (2005) 107-118. Available online: http://dx.doi.org/10.1111/j.1442-2018.2005.00227.x.

[26] M. Small, L. Bailey-Davis, N. Morgan, J. Maggs, and Changes in eating and physical activity behaviors across seven semesters of college: living on or off campus matters, Health Education \& Behavior 40 (2013) 435-441. Available online: http://dx.doi.org/10.1177/1090198112467801.

[27] S.R. Bray, H.A. Born, Transition to university and vigorous physical activity: implications for health and psychological well-being, Journal of American College Health 52 (2004) 181-188. Available online: http://dx.doi.org/10.3200/JACH.52.4.181-188.

[28] X.D. Keating, J. Guan, J.C. Piñero, D.M. Bridges, A meta-analysis of college students' physical activity behaviors, Journal of American College Health 54 (2005) 116-125. Available online: http://dx.doi.org/10.3200/JACH.54.2.116-126.

[29] American College Health Association, National College Health Assessment II: Reference Group Executive Summary Fall 2010. American College Health Association, Linthicum, MD, 2011. Available online: http://www.acha-ncha.org/reports_acha-nchaii.html. 
[30] R. Vella-Zarb, F. Elgar, The 'Freshman 5': a meta-analysis of weight gain in the freshman year of college. Journal of American College Health 58 (2009) 161-166. Available online: http://dx.doi.org/10.1080/07448480903221392.

[31] S. Racette, S. Deusinger, M. Strube, G. Highstein, R. Deusinger, Changes in weight and health behaviors from freshman through senior year of college, Journal of Nutrition Education and Behavior 40 (2008) 39-42. Available online: http://dx.doi.org/10.1016/j.jneb.2007.01.001

[32] M. Nelson, R. Kocos, L. Lytle, C. Perry, Understanding the perceived determinants of weight-related behaviors in late adolescence: a qualitative analysis among college youth, Journal of Nutrition Education and Behavior 41 (2009) 287-292. Available online: http://dx.doi.org/10.1016/j.jneb.2008.05.005

[33] M. Greaney, F. Less, A. White, et al., College students' barriers and enablers for healthful weight management: a qualitative study, Journal of Nutrition Education and Behavior 41 (2009) 281-286. Available online: http://dx.doi.org/10.1016/j.jneb.2008.04.354.

[34] I. Holsen, D. Carlson Jones, M. Skogbrott Birkeland, Body image satisfaction among Norwegian adolescents and young adults: a longitudinal study of the influence of interpersonal relationships and BMI, Body Image 9 (2012) 201-208. Available online: http://dx.doi.org/10.1016/j.bodyim.2012.01.006. Epub 2012 Mar 4.

[35] F. Al-Kandari, V.L. Vidal, D. Thomas, Health-promoting lifestyle and body mass index among College of Nursing students in Kuwait: a correlational study, Nursing \& Health Sciences 10 (2008) 43-50. Available online: http://dx.doi.org/10.1111/j.1442-2018.2007.00370.x.

[36] S.L. Huang, R.H. Li, F.C. Tang, Comparing disparities in the health-promoting lifestyles of Taiwanese workers in various occupations. Industrial Health 48 (2010) 256-64. Available online: http://dx.doi.org/10.2486/indhealth.48.256.

[37] M.E. Wilkosz, J.L. Chen, C. Kenndey, S. Rankin, Body dissatisfaction in California adolescents, Journal of the American Academy of Nurse Practitioners 23 (2011) 101-109. Available online: http://dx.doi.org/10.1111/j.1745-7599.2010.00586.x.

[38] Physical Activity Guidelines Advisory Committee, 2008 Physical Activity Guidelines for Americans., U.S. Department of Health and Human Services, Washington DC, 2008. Available online: www.health.gov/paguidelines/.

[39] J.J. Prochaska, J.F. Sallis, B. Long, A physical activity screening measure for use with adolescents in primary care. Archives of Pediatric Adolescent Medicine 155 (2001) 554-549. Available online: http://dx.doi.org/10.1001/archpedi.155.5.554.

[40] S.N. Walker, D.M. Hill-Polerecky, Psychometric evaluation of the Health-Promoting Lifestyle Profile II (unpublished manuscript),

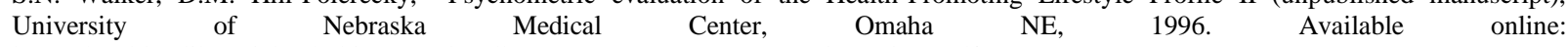
http://deepblue.lib.umich.edu/bitstream/handle/2027.42/85349/HPLP II-Dimensions.pdf?sequence=2.

[41] S.N. Walker, K.R. Sechrist, N.J. Pender, The Health-Promoting Lifestyle Profile: development and psychometric characteristics. Nursing Research 36 (1987) 76-81. Available online: http://dx.doi.org/10.1097/00006199-198703000-00002.

[42] G. Can, K. Ozdilli, O. Erol, et al., Comparison of the health-promoting lifestyles of nursing and non-nursing students in Istanbul, Turkey, Nursing \& Health Sciences 10 (2008) 273-280. Available online: http://dx.doi.org/10.1111/j.1442-2018.2008.00405.x.

[43] S.M. Ulla Díez, A. Pérez-Fortis, Socio-demographic predictors of health behaviors in Mexican college students. Health Promotion International 25 (2010) 85-93. Available online: http://dx.doi.org/10.1093/heapro/dap047.

[44] M.A. Stark, J. Manning-Walsh, S. Vliem, Caring for self while learning to care for others: a challenge for nursing students, Journal of Nursing Education 44 (2005) 266-270.

[45] S. Keller, J.E. Maddock, W. Hannöver, J.R. Thyrian, H.D. Basler, Multiple health risk behaviors in German first year university students., Preventive Medicine 46 (2008) 189-195. Available online: http://dx.doi.org/10.1016/j.ypmed.2007.09.008.

[46] D. Neumark-Sztainer, S.J. Paxton, P.J. Hannan, J. Haines, M. Story, Does body satisfaction matter? Five-year longitudinal associations between body satisfaction and health behaviors in adolescent females and males, Journal of Adolescent Health 39 (2006) 244-2 51. Available online: http://dx.doi.org/10.1016/j.jadohealth.2005.12.001. 